Artigo

\title{
Leiam, meninos! Uma análise das materialidades do livro e do conteúdo dos best-sellers para crianças e pré-adolescentes do sexo masculino, entre 8 e 12 anos
}

\author{
Read, boys! An analysis of the materialities of the book and the \\ content of the best-sellers for male children and pre-adolescents, \\ between 8 and 12 years old
}

\section{Marcelo Amaral de Moraes'}

'Centro Federal de Educação Tecnológica de Minas Gerais, Minas Gerais, MG, Brasil

\section{RESUMO}

Este artigo investiga, a partir da materialidade e do conteúdo dos livros de um corpus composto por bestsellers infantojuvenis, quais são os elementos editoriais que potencialmente contribuem para o sucesso editorial de um livro para meninos na faixa etária entre 8 e 12 anos. A pretensão deste estudo é contribuir para uma compreensão maior das motivações dessas crianças e pré-adolescentes do sexo masculino para a leitura, no intuito de subsidiar a curadoria de títulos estrangeiros para publicação no mercado brasileiro e a produção de títulos nacionais para esse público.

Palavras-chave: Edição; Literatura infanto-juvenil; Leitura; Leitor; Best-seller

\section{ABSTRACT}

This paper investigates, from the materiality and the content of the books of a corpus composed of children and youth bestsellers, what are the editorial elements that potentially contribute to the editorial success of a book for boys between 8 and 12 years old. The purpose of this study is to contribute to a greater understanding of the motivations of these children and pre-adolescents of the male sex for reading, in order to subsidize the curatorship of foreign titles for publication in the Brazilian market and the production of national titles for this public.

Keywords: Publishing; Children's and Youth Literature; Reading; Reader; Best-seller 


\section{INTRODUÇÃO}

Este artigo surgiu da inquietação quanto à hipótese de que os meninos leem menos do que as meninas. Supondo-se que esta hipótese seja verdadeira, pergunta-se, neste estudo, o que poderia ser feito em termos de produção editorial para que os livros se tornassem mais atraentes aos olhos dos meninos e, com isso, fossem capazes de fisgá-los a ponto de convertê-los em leitores frequentes.

É claro que se trata de uma questão complexa e multifacetada, o que leva a contribuições incrementais na busca por uma resposta, que jamais terá um único ponto de vista.

A tese central deste artigo é a de que é possível, sim, identificar os fatores de atratividade e de engajamento com o livro para o leitor do sexo masculino na faixa etária entre 8 e 12 anos.

O método de pesquisa usado partiu do final, ou seja, de livros notadamente atraentes e engajadores para esse público, que constituíram o corpus de análise. Essas obras foram decupadas em aspectos biblioteconômicos, morfológicos, entre outros, para que, analisando-se semelhanças e diferenças, inferissem-se alguns "caminhos" para investigações futuras, em maior profundidade, em cada um desses elementos apurados.

\section{QUEM SÃO AS CRIANÇAS E OS PRÉ-ADOLESCENTES?}

No Brasil, o Estatuto da Criança e do Adolescente considera criança a pessoa que tem até 12 anos incompletos, e adolescente a que tem de 12 anos completos até 18 anos incompletos. Não há, portanto, definição de pré-adolescência, que ficaria ali entre os 10 e 12 anos, e que assim consideraremos neste artigo.

Entretanto, do ponto de vista da leitura, há outras questões envolvidas, pois a adolescência, assim como a infância, são conceitos socialmente construídos e que variam dependendo da cultura, do nível social, da escolaridade e de outros 
fatores. A pesquisadora Marta Passos Pinheiro, em seu texto Literatura infantil e juvenil: uma reflexão sobre a construção, assim define "o infantil e o juvenil" em relação à literatura:

$\mathrm{O}$ adjetivo infantil e, mais recentemente, o juvenil atrelados à literatura caracterizam o público a que se destina essa produção cultural: a criança e o jovem (adolescente). A construção dessas fases da vida está diretamente relacionada ao modelo burguês de família e à escola moderna. A função que foi atribuída à literatura infantil e juvenil pode ser melhor compreendida através da análise da forma como a relação entre infância, e mais tarde adolescência, escola e literatura foi sendo estabelecida. (PINHEIRO, 2008, on-line).

Pinheiro (2008) ainda ressalta que o conceito de infância e adolescência se imbricou com o de escolarização, ou seja, a introdução e a consolidação do ensino seriado, no qual para cada série há uma determinada idade correspondente, forjaram a ideia de que as fases definidas pelo binômio série-idade são naturais.

A separação dos alunos, por idade, em classes escolares contribuiu para a definição da segunda infância e da adolescência. Quanto menor for a divisão em classes, menor será a divisão dos alunos. Em um lugar em que só exista o ensino primário, como definir (separar) a segunda infância da adolescência? Isso nos leva a refletir sobre o papel da escola na definição e separação de determinadas fases da vida, como a infância e a adolescência. (PINHEIRO, 2008, on-line).

Qualquer que seja o corte etário usado para se classificar o que é uma criança ou um adolescente, sempre será uma entre muitas opções. Mesmo assim, é necessário que tal escolha seja feita para que a análise do objeto seja viável do ponto de vista metodológico.

Neste artigo, a faixa etária analisada será a de crianças e pré-adolescentes entre 8 e 12 anos, mirando-se especialmente nos que estão cursando do $3^{\circ}$ ano do ensino fundamental (8 a 9 anos) ao $7^{\circ}$ ano (12 a 13 anos), conforme Quadro 1 a seguir. 
Quadro 1 - Anos e idades correspondentes do ensino fundamental brasileiro

\begin{tabular}{|l|}
\hline Ensino fundamental \\
\hline $\mathbf{1}^{\circ}$ Ano: 6 anos completos até 31 de março do ano letivo. \\
\hline $\mathbf{2}^{\circ}$ Ano: de 7 a 8 anos. \\
\hline $\mathbf{3}^{\circ}$ Ano: de 8 a 9 anos. \\
\hline $\mathbf{4}^{\circ}$ Ano: de 9 a 10 anos. \\
\hline $\mathbf{5}^{\circ}$ Ano: de 10 a 11 anos. \\
\hline $\mathbf{6}^{\circ}$ Ano: de 11 a 12 anos. \\
\hline $\mathbf{7}^{\circ}$ Ano: de 12 a 13 anos. \\
\hline $\mathbf{8}^{\circ}$ Ano: de 13 a 14 anos. \\
\hline $\mathbf{9}^{\circ}$ Ano: de 14 a 15 anos. \\
\hline
\end{tabular}

Fonte: elaborado pelo autor a partir de BRASIL (2018).

Essa escolha foi feita para se partir de um ponto em que, supostamente, as crianças já estivessem alfabetizadas e com fluência suficiente para ler os livros escolhidos para o corpus deste artigo.

Esses primeiros anos de formação do leitor são cruciais para que ele tome gosto pela leitura e internalize esse hábito, não apenas como uma tarefa ou obrigação escolar, mas também como fonte de lazer.

A pesquisa Retratos da Leitura no Brasil mostra que o gosto pela leitura é relativamente forte na criança nos primeiros anos do ensino fundamental, mas decresce significativamente à medida que o aluno avança rumo ao ensino médio. Por que será que isso acontece? E, mesmo que não haja uma resposta simples - e por certo não há -, em que medida tornar o livro mais atrativo para esse público pode impactar no aumento dos índices de leitura?

\section{POR QUE OS MENINOS?}

Apesar da escassez de informações e de pesquisas mais aprofundadas sobre as diferenças entre crianças e pré-adolescentes dos sexos masculino e feminino, no que tange às práticas de leitura, há algumas referências nesse sentido. 
No artigo Reading motivation: exploring the elementary gender gap (MARINAK; GRAMBRELL, 2010), as pesquisadoras salientam algumas diferenças entre meninas e meninos. Segundo elas, por exemplo, meninas gostam muito mais de ler do que meninos, e meninos são mais afeitos ao gênero quadrinhos e livros com apelo humorístico, conforme excerto a seguir:

Este estudo explorou as atitudes de meninas e meninos (de 10-11 anos) em relação à leitura e à escrita. As meninas gostavam muito mais de ler do que os meninos. Os meninos gostavam sobretudo de quadrinhos e livros humorísticos; os livros de aventura eram os preferidos das meninas. A poesia não agradava aos alunos. Muitos meninos não gostavam dos textos típicos escolares. A maioria dos alunos, especialmente os meninos, não gostava de ler em voz alta. Mesmo muitos leitores fluentes e motivados sentiam-se envergonhados quando liam em voz alta. As atitudes dos alunos em relação à escrita eram mais negativas do que as atitudes em relação à leitura. Os meninos eram escritores significativamente mais relutantes do que as meninas. Para interessar os meninos, a tarefa de escrever deveria ter um propósito ou uma função comunicativa significativa. Os resultados sugerem que o interesse dos alunos deve ser um fator chave na escolha do material de leitura; caso contrário, muitos alunos evitarão a leitura e poderão desenvolver uma aversão vitalícia à mesma. (MARINAK; GRAMBRELL, 2010, on-line, tradução nossa).

Outra pesquisa, desenvolvida pelo The Brown Center on Education Policy, identificou uma lacuna entre o desempenho de meninas e de meninos nas pontuações do Program for International Student Assessment (PISA). O mais curioso é que esse fenômeno ocorre em vários países e persiste há décadas. Nesse mesmo estudo, são analisadas causas potenciais para a existência dessa lacuna, desde aspectos biológicos e de desenvolvimento até práticas escolares e influências culturais.

A escritora Peg Tyre, em The trouble with boys: a surprising report card on our sons, their problems at school, and what parents and educators must do, defende a tese de que o desenvolvimento dos meninos se dá mais tardiamente do que o das meninas, o que os levaria, em salas nas quais as professoras são predominantemente do sexo feminino, a ficar para trás nas disciplinas que tratam da leitura e da escrita. Tal defasagem supostamente levaria os meninos a perder 
gradativamente o interesse pela leitura, por não se sentirem confortáveis e/ou por se julgarem fracassados, estimulando-os a focar em áreas como ciências e matemática, por exemplo.

Essas pesquisas ensejam um elemento fundamental na busca pela "captura" do leitor, a motivação. Em Kids \& family reading report - 7th edition - finding their story, da editora SCHOLASTIC, nos Estados Unidos, em 2018, foram entrevistados 2.758 pais e crianças; $89 \%$ das crianças que responderam à pesquisa concordaram com a afirmação: "Meus livros preferidos são os que eu escolhi por conta própria". Considerando todos os aspectos mencionados, acredita-se haver elementos suficientes que justifiquem a escolha do estrato "meninos entre 8 e 12 anos de idade" como foco deste estudo.

\section{O CORPUS E A METODOLOGIA}

Este estudo selecionou seis livros considerados best-sellers para meninos entre 8 e 12 anos de idade, o que não significa que meninas também não os leiam, mas apenas que são obras que encontram, em crianças e pré-adolescentes do sexo masculino, boa aceitação.

O corpus selecionado (ver Quadro 2) é propositalmente bastante diversificado quanto à materialidade, às temáticas, aos estilos, às imagens, ao conteúdo, entre outros aspectos observáveis. A quantidade de seis títulos é pequena, mas suficiente para os objetivos deste artigo.

Sobre esse corpus foi aplicada a metodologia de análise de conteúdo, na qual o pesquisador identificou, rotulou e quantificou vários aspectos pretendidos dos livros para, a seguir, compará-los e tecer comentários e análises que ajudassem a elucidar potenciais fatores contribuintes para que esses títulos se mostrem tão atraentes para o público pesquisado. Com isso, buscou-se extrair elementos que pudessem ser reproduzidos em outros livros, seja por meio de novas traduções, seja em obras nacionais originais, de forma a contribuir para a oferta de títulos 
que estimulem o aumento da quantidade de leitores e da frequência de leitura desses "meninos".

Quadro 2 - Corpus selecionado para análise

\begin{tabular}{|c|c|c|c|c|c|c|}
\hline Título & Amoras & Crônicas 1 & $\begin{array}{c}\text { Diário de Pilar } \\
\text { na Grécia }\end{array}$ & $\begin{array}{l}\text { Diário de um } \\
\text { banana }\end{array}$ & $\begin{array}{c}\text { Malala, a } \\
\text { menina que } \\
\text { queria ir para } \\
\text { a escola }\end{array}$ & $\begin{array}{c}\text { O rapto do } \\
\text { garoto de ouro }\end{array}$ \\
\hline Capa & & $\theta^{\circ}$ & 18var & $\begin{array}{l}\text { DIARIO } \\
\text { Bañana } \\
\text { a. }\end{array}$ & MALALA & 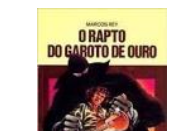 \\
\hline Autor & Emicida & $\begin{array}{c}\text { Carlos } \\
\text { Drummond } \\
\text { de Andrade } \\
\text { [et. al.] }\end{array}$ & $\begin{array}{l}\text { Flávia Lins e } \\
\text { Silva }\end{array}$ & Jeff Kinney & $\begin{array}{l}\text { Adriana } \\
\text { Carranca }\end{array}$ & Marcos Rey \\
\hline Ilustrador & Aldo Fabrini & Jaca & Joana Penna & Jeff Kinney & $\begin{array}{c}\text { Bruna Assis } \\
\text { Brasil }\end{array}$ & $\mathrm{N} / \mathrm{l}$ \\
\hline Selo & $\begin{array}{c}\text { Companhia } \\
\text { das Letrinhas }\end{array}$ & Ática & $\begin{array}{l}\text { Pequena } \\
\text { Zahar }\end{array}$ & $\begin{array}{c}\text { Vergara e } \\
\text { Ribas Editora }\end{array}$ & $\begin{array}{l}\text { Companhia } \\
\text { das Letrinhas }\end{array}$ & Ática \\
\hline Edição & $1^{\text {a Edição }}$ & 28 Ediç̧ão & $2^{a}$ Edição & $1^{\text {a }}$ Edição & $1^{\text {a Edição }}$ & $5^{a}$ Edição \\
\hline Cidade & São Paulo & São Paulo & Rio de Janeiro & Cotia & São Paulo & São Paulo \\
\hline Ano & 2020 & 2011 & 2018 & 2012 & 2019 & 1985 \\
\hline
\end{tabular}

Fonte: elaborado pelo autor.

Depois de selecionadas, as obras foram integralmente escaneadas, usandose um scanner de mesa Fujitsu Color, A3 - SV600 e o software ScanSnap. Após escaneados, os livros passaram por um processo de conversão de imagem para PDF editável, usando-se o software PowerPDF, com tecnologia Optical Character Recognition (OCR). Uma vez convertido, o arquivo foi importado para o software de análise de conteúdo ATLAS.ti (versão 8.4), no qual foram registrados os dados quantitativos, os rótulos de dados e outros elementos de análise do conteúdo, foco deste estudo, que serão apresentados mais adiante. 


\section{RESULTADOS}

Após os procedimentos mencionados, os resultados foram tabulados e analisados em grupos de dados, conforme a avaliação de compradores e/ou leitores, os aspectos biblioteconômicos, a morfologia e outros fatores que não se encaixam nas categorias mencionadas.

\subsection{Por que se diz que esses seis títulos são best-sellers?}

A denominação best-seller é normalmente atribuída a livros que vendem muito acima da média. Embora não haja uma definição clara do que seja muito, e conquanto "muito" seja um conceito extremamente relativo, dependendo do gênero editorial, do mercado ou do país onde o livro é comercializado, não há, de fato, critérios suficientemente objetivos para se afirmar que determinado título é ou não um best-seller.

Entretanto, assim como acontece com outras designações que são feitas "na prática", se as evidências de que o livro é um best-seller aparecerem em fontes de informação diferentes e independentes, é razoável supor que ele seja realmente um legítimo "mais vendido". Para este artigo, optou-se por confirmar essa designação por meio da verificação da quantidade de reviews - número de pessoas que atribuíram uma nota de 1 a 5 para um livro - e a nota média, de 1 a 5 pontos, no marketplace da Amazon.com.br e nas redes sociais especializadas em livros: Goodreads.com e Skoob.com.br.

É importante observar que quanto maior o número de reviews, mais estável é a nota média, pois a base de clientes "votantes" é maior, o que dá mais confiabilidade estatística para a métrica. Outro ponto relevante é considerar o tempo de mercado do livro. Por exemplo, o livro Crônicas 1, o mais antigo entre os títulos do corpus, teve sua $1^{\text {a }}$ edição em 1977, enquanto Amoras foi lançado em 2018, ou seja, há um intervalo de mais de 40 anos entre um e outro. 
Logo, é razoável supor que os livros mais recentes tenham menos reviews, ainda que se saiba que a possibilidade de se fazerem reviews nos sites de e-commerce nas redes sociais é um fenômeno relativamente recente, que se tornou mais comum de uns 10 anos para cá.

Outra consideração a se fazer é a de que a maioria das avaliações registradas no site Amazon é de compradores, pois trata-se de um site de e-commerce em que os clientes são instados a avaliar os livros algumas semanas após a compra.

Já os sites Goodreads.com.br e Skoob.com.br são redes sociais - e não lojas virtuais como a Amazon - formadas por pessoas que se interessam por livros e que, não necessariamente, são compradoras. A quantidade de reviews na rede Skoob, em todos os títulos analisados, supera com larga vantagem a da Goodreads e a da Amazon, talvez porque o Skoob seja um site genuinamente brasileiro, enquanto os outros são estrangeiros.

Quadro 3 - Quantidade de reviews e avaliação média dos livros pelos leitores e compradores

\begin{tabular}{|c|c|c|c|c|c|c|}
\hline Título & Amoras & Crônicas 1 & $\begin{array}{l}\text { Diário de Pilar } \\
\text { na Grécia }\end{array}$ & $\begin{array}{l}\text { Diário de um } \\
\text { banana }\end{array}$ & $\begin{array}{c}\text { Malala, a } \\
\text { menina que } \\
\text { queria ir para } \\
\text { a escola }\end{array}$ & $\begin{array}{l}\text { O rapto do } \\
\text { garoto de } \\
\text { ouro }\end{array}$ \\
\hline Capa & Allulito & $\theta^{\circ}=$ & Pilar & $\begin{array}{l}\text { DIARIO } \\
\text { Banana } \\
x^{3}\end{array}$ & $\frac{\text { MALALA }}{\operatorname{mag}}$ & \\
\hline $\begin{array}{l}\text { Reviews } \\
\text { Amazon }\end{array}$ & 1.615 & 52 & 347 & 401 & 1.165 & 61 \\
\hline Nota Amazon & 4,80 & 4,80 & 4,70 & 4,70 & 4,80 & 4,80 \\
\hline Reviews Skoob & 2.041 & 1.678 & 2.041 & 19.421 & 875 & 5.310 \\
\hline Nota Skoob & 4,40 & 3,90 & 4,40 & 4,00 & 4,20 & 3,70 \\
\hline $\begin{array}{c}\text { Reviews } \\
\text { Goodreads }\end{array}$ & 798 & 218 & 148 & 20.058 & 158 & 555 \\
\hline $\begin{array}{c}\text { Nota } \\
\text { Goodreads }\end{array}$ & 4,40 & 4,19 & 4,40 & 4,00 & 4,34 & 3,77 \\
\hline
\end{tabular}

Fonte: elaborado pelo autor. Dados coletados em 26 de novembro de 2020. 
É importante ainda pontuar que, nas redes sociais, a participação dos leitores menores de idade é maciça, o que não ocorre no site da Amazon, no qual é necessário que um indivíduo tenha 18 anos para que possa efetuar compras com cartão de crédito e reviews verificados - o que acaba inibindo a participação de crianças e pré-adolescentes.

Todos os seis títulos do corpus receberam avaliações médias acima de 4 pontos - as notas vão de 1 a 5 pontos - em pelo menos uma dessas três plataformas, e uma quantidade de reviews superior a 100, o que indica um nível de engajamento elevado para livros. Por isso, é possível inferir que esses seis títulos infantojuvenis são livros de grande aceitação por leitores e compradores e, portanto, best-sellers.

\subsection{Aspectos biblioteconômicos}

Neste artigo foram considerados aspectos biblioteconômicos todos os itens da primeira coluna do Quadro 4. A começar pelos dois primeiros, capa e título, tem-se aí dois dos aspectos mais relevantes na escolha de livros em geral e, notadamente, da categoria infantojuvenil.

Quadro 4 - Aspectos biblioteconômicos dos livros do corpus

\begin{tabular}{|c|c|c|c|c|c|c|}
\hline Título & Amoras & Crônicas 1 & $\begin{array}{c}\text { Diário de Pilar } \\
\text { na Grécia }\end{array}$ & $\begin{array}{l}\text { Diário de um } \\
\text { banana }\end{array}$ & $\begin{array}{c}\text { Malala, a } \\
\text { menina que } \\
\text { queria ir para } \\
\text { a escola }\end{array}$ & $\begin{array}{l}\text { O rapto do } \\
\text { garoto de } \\
\text { ouro }\end{array}$ \\
\hline Capa & & $\theta^{\circ}=$ & Pilar & $\begin{array}{c}\text { DIÁRIO } \\
\text { Banâna } \\
7 \\
7^{3}\end{array}$ & $\frac{\text { MALALA }}{30}$ & \\
\hline Autor & Emicida & $\begin{array}{c}\text { Carlos } \\
\text { Drummond } \\
\text { de Andrade } \\
\text { [et. al.] }\end{array}$ & $\begin{array}{l}\text { Flávia Lins e } \\
\text { Silva }\end{array}$ & Jeff Kinney & $\begin{array}{l}\text { Adriana } \\
\text { Carranca }\end{array}$ & Marcos Rey \\
\hline Ilustrador & Aldo Fabrini & Jaca & Joana Penna & Jeff Kinney & $\begin{array}{c}\text { Bruna Assis } \\
\text { Brasil }\end{array}$ & $N / \mathrm{l}$ \\
\hline
\end{tabular}




\begin{tabular}{|c|c|c|c|c|c|c|}
\hline Tradutor & Não aplicável & Não aplicável & Não aplicável & $\begin{array}{c}\text { Antônio de } \\
\text { Macedo } \\
\text { Soares } \\
\end{array}$ & Não aplicável & Não aplicável \\
\hline Selo & $\begin{array}{c}\text { Companhia } \\
\text { das Letrinhas }\end{array}$ & Ática & $\begin{array}{c}\text { Pequena } \\
\text { Zahar }\end{array}$ & $\begin{array}{c}\text { Vergara e } \\
\text { Ribas Editora }\end{array}$ & $\begin{array}{c}\text { Companhia } \\
\text { das Letrinhas }\end{array}$ & Ática \\
\hline Grupo Editorial & $\begin{array}{c}\text { Grupo } \\
\text { Companhia } \\
\text { das Letras }\end{array}$ & $\begin{array}{l}\text { Grupo Ática } \\
\text { Scipione }\end{array}$ & $\begin{array}{c}\text { Grupo } \\
\text { Companhia } \\
\text { das Letras }\end{array}$ & VR Editora & $\begin{array}{c}\text { Grupo } \\
\text { Companhia } \\
\text { das Letras }\end{array}$ & $\begin{array}{l}\text { Grupo Ática } \\
\text { Scipione }\end{array}$ \\
\hline Edição & $1^{\text {a }}$ Edição & 28 Edição & $2^{a}$ Edição & $1^{\text {a }}$ Edição & $1^{\text {a }}$ Edição & $5^{\text {a Edição }}$ \\
\hline Cidade & São Paulo & São Paulo & $\begin{array}{l}\text { Rio de } \\
\text { Janeiro }\end{array}$ & Cotia & São Paulo & São Paulo \\
\hline Ano & 2020 & 2011 & 2018 & 2012 & 2019 & 1985 \\
\hline Ano do original & 2018 & 1977 & 2010 & 2007 & 2015 & 1982 \\
\hline $\mathrm{N}^{\circ}$ de páginas & 44 & 102 & 154 & 218 & 96 & 128 \\
\hline ISBN-10 & 8574068365 & 8508130627 & 8566642406 & 8576831309 & 8574066702 & 8526009966 \\
\hline ISBN-13 & $\begin{array}{c}978- \\
8574068367 \\
\end{array}$ & $\begin{array}{c}978- \\
8508130627 \\
\end{array}$ & $\begin{array}{c}978- \\
8566642407 \\
\end{array}$ & $\begin{array}{c}978- \\
8576831303 \\
\end{array}$ & $\begin{array}{c}978- \\
8574066707 \\
\end{array}$ & $\begin{array}{c}978- \\
8526009967 \\
\end{array}$ \\
\hline Idioma avaliado & Português & Português & Português & Português & Português & Português \\
\hline Assunto & $\begin{array}{c}\text { Poesia - } \\
\text { Literatura } \\
\text { infantojuveni } \\
\text { l; Poesia - } \\
\text { Literatura } \\
\text { infantil } \\
\end{array}$ & Crônicas & $\begin{array}{c}\text { Ficção } \\
\text { infantojuveni } \\
\text { I brasileira }\end{array}$ & $\begin{array}{c}\text { Literatura } \\
\text { infantojuveni } \\
\text { I; Literatura } \\
\text { juvenil }\end{array}$ & $\begin{array}{c}\text { Biografia - } \\
\text { Literatura } \\
\text { infantojuveni } \\
\text { । }\end{array}$ & $\begin{array}{c}\text { Literatura } \\
\text { infantojuveni } \\
\text { I }\end{array}$ \\
\hline Reimpressão & $11^{\mathrm{a}}$ reimp. & $13^{\mathrm{a}}$ reimp. & $\begin{array}{l}4^{a} \text { reimp.da } \\
2^{a} \text { edição }\end{array}$ & $\begin{array}{c}\text { Não } \\
\text { informado }\end{array}$ & $19^{\mathrm{a}}$ reimp. & $\begin{array}{c}\text { Não } \\
\text { informado }\end{array}$ \\
\hline CDD & 028.5 & 86.998 .008 & 028.5 & 028.5 & 028.5 & 028.5 \\
\hline
\end{tabular}

Fonte: elaborado pelo autor.

De acordo com dados da pesquisa Retratos da leitura no Brasil (Figura 1), a capa foi citada por $10 \%$ dos entrevistados como um dos fatores que mais influenciam na escolha de um livro. No entanto, para a faixa de 5 a 10 anos de idade, esse número é quase o triplo, alcançando 29\% dos respondentes, evidenciando a importância da adequação e da atratividade da capa para os leitores infantojuvenis. 
Figura 1 - Importância da capa e do título para os leitores infantojuvenis

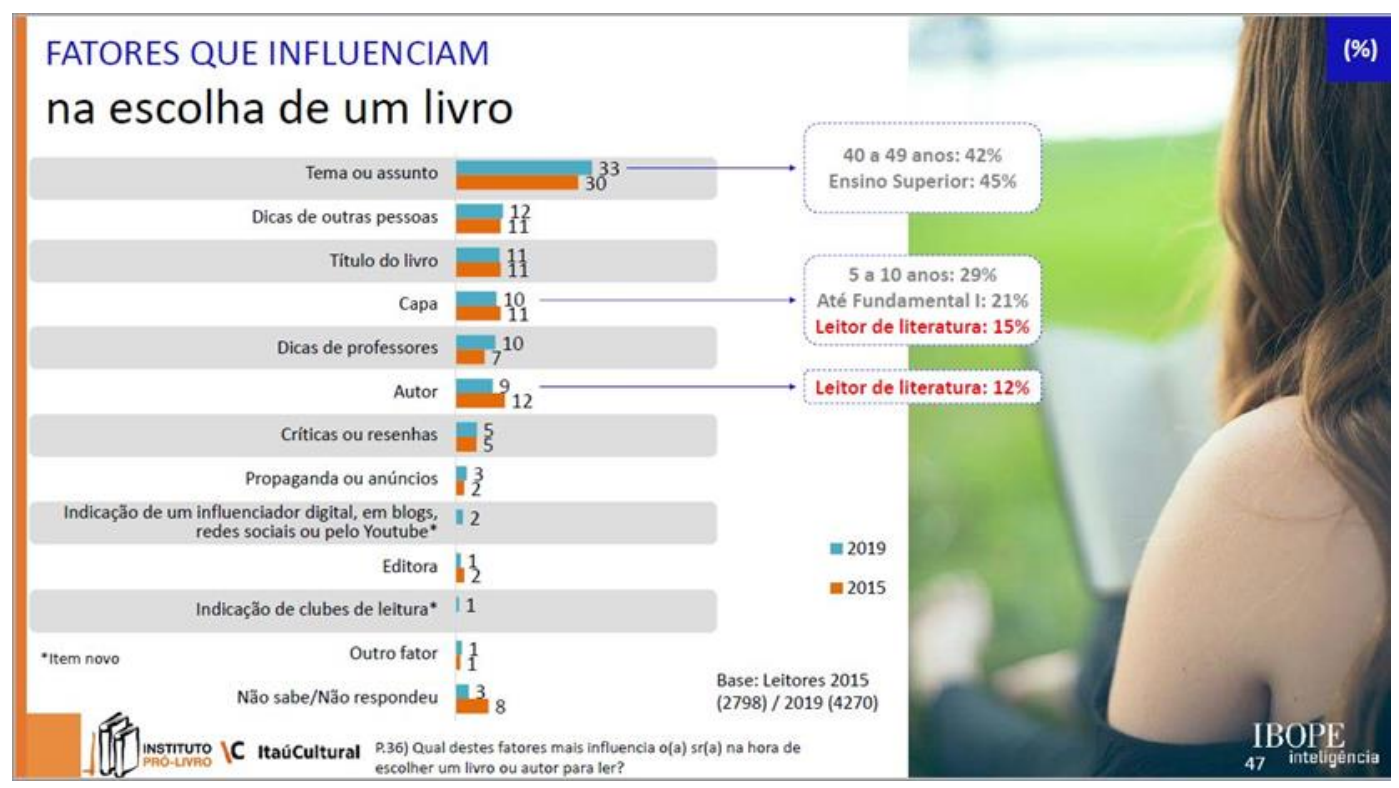

Fonte: INSTITUTO PRÓ-LIVRO (2020)

Não menos importante, o título do livro ocupa o terceiro lugar geral em relação aos fatores influentes na decisão de escolha da obra, tendo sido mencionado por $11 \%$ dos respondentes.

Todos os livros pesquisados no corpus, à exceção de Crônicas 1, foram classificados sob o código 028.5 da classificação decimal de Dewey, ou código CDD, que é a numeração para a classe de livros infantojuvenis. Isso significa que todos os títulos foram originalmente destinados, prioritariamente, ao público infantojuvenil, com exceção do de crônicas, que embora seja lido também por essa faixa etária - especialmente na escola, como leitura sugerida -, é um livro extensivo a praticamente todos os tipos de leitores, em termos de faixa etária.

O número de páginas é outro atributo que, nos livros infantojuvenis, apresenta comportamento típico. Em geral, essas obras não ultrapassam 150 páginas, mesmo sendo impressas em formatos menores, com margens mais largas, espaço entrelinhas generoso, corpo da fonte maior e muitas ilustrações. 
As ilustrações, essas sim, constituem um aspecto predominante nos livros infantojuvenis. Há uma abundância delas, muito mais do que na maioria dos outros gêneros editoriais. A relação do leitor dessa faixa etária (8 a 12 anos) com o aspecto imagético representa um poderoso fator de atração, o que ficou evidente pela quantidade de imagens em relação ao número total de páginas do livro, especialmente no caso de Diário de um banana, em que a média de ilustrações por página é cerca de 1,5.

Os demais fatores biblioteconômicos, para além da capa, do título e das ilustrações, representam elementos secundários na escolha do livro para o público infantojuvenil, a partir da análise da pesquisa Retratos da leitura no Brasil.

\subsection{Aspectos morfológicos}

Quanto à forma dos livros analisados, pode-se perceber a predominância de alguns aspectos. As fontes empregadas são relativamente grandes se comparadas às de outros gêneros editoriais, assim como o espaçamento entrelinhas e as margens, que são generosas. O destaque fica para Diário de um banana, que apresenta uma fonte "manuscrita", a Wimpy Kid. Em seu canal no YouTube, o autor, Jeff Kenney, declara que escrever seus livros usando essa fonte o faz "entrar no clima" e o ajuda na criação dos textos.

Quadro 5 - Aspectos morfológicos dos livros do corpus

\begin{tabular}{|c|c|c|c|c|c|c|}
\hline Título & Amoras & Crônicas 1 & $\begin{array}{c}\text { Diário de } \\
\text { Pilar na } \\
\text { Grécia }\end{array}$ & $\begin{array}{l}\text { Diário de um } \\
\text { banana }\end{array}$ & $\begin{array}{c}\text { Malala, a } \\
\text { menina que } \\
\text { queria ir para } \\
\text { a escola }\end{array}$ & $\begin{array}{l}\text { O rapto do } \\
\text { garoto de } \\
\text { ouro }\end{array}$ \\
\hline Capa & & $0^{6}$ & Pilar & $\begin{array}{l}\text { DIARIO } \\
\text { Banana } \\
\text { *. }\end{array}$ & MALALA & \\
\hline Fonte & $\begin{array}{l}\text { Eames } \\
\text { Century } \\
\text { Mode }\end{array}$ & Electra & Baskerville & Whimpy Kid & Weiss & $\begin{array}{c}\text { Times New } \\
\text { Roman }\end{array}$ \\
\hline
\end{tabular}


68 | Leiam, meninos! Uma análise das materialidades do livro e do conteúdo dos best-sellers para crianças e pré-adolescentes do sexo masculino, entre 8 e 12 anos

\begin{tabular}{|c|c|c|c|c|c|c|}
\hline Papel & $\begin{array}{l}\text { Alta Alvura } \\
\text { (Suzano) }\end{array}$ & $\begin{array}{l}\text { Pólen Bold } \\
90 \mathrm{~g} / \mathrm{m} 2\end{array}$ & $\begin{array}{c}\text { Couché } \\
\text { Matte } \\
115 \mathrm{~g} / \mathrm{m} 2\end{array}$ & $\begin{array}{c}\text { Não } \\
\text { informado }\end{array}$ & $\begin{array}{l}\text { Alta Alvura } \\
\text { (Suzano) }\end{array}$ & $\begin{array}{c}\text { Não } \\
\text { informado }\end{array}$ \\
\hline Cor da capa & Colorida & Colorida & Colorida & Colorida & Colorida & Colorida \\
\hline Cor do miolo & Colorido & Bicolor & Colorido & $P \& B$ & $\begin{array}{c}\text { P\&B e } \\
\text { Colorido }\end{array}$ & $P \& B$ \\
\hline $\begin{array}{c}\text { Acabamento } \\
\text { especial }\end{array}$ & $\begin{array}{l}\text { Laminação } \\
\text { fosca }\end{array}$ & $\begin{array}{l}\text { Laminação } \\
\text { fosca }\end{array}$ & $\begin{array}{l}\text { Laminação } \\
\text { fosca }\end{array}$ & $\begin{array}{c}\text { Verniz } \\
\text { localizado }\end{array}$ & $\begin{array}{l}\text { Laminação } \\
\text { fosca }\end{array}$ & Nenhum \\
\hline Brochura & Sim & Sim & Sim & Não & Sim & Sim \\
\hline Capa dura & Não & Não & Não & Sim & Não & Não \\
\hline Orelha & Não & Não & Não & Não & Não & Sim \\
\hline $\begin{array}{c}\text { Impressão capa } \\
\text { interna }\end{array}$ & Não & Sim & Sim & Sim & Não & Não \\
\hline Tamanho & $\begin{array}{c}20,6 \times 20,6 \times \\
0,5 \mathrm{~cm}\end{array}$ & $\begin{array}{c}20,6 \times 14,0 x \\
0,9 \mathrm{~cm}\end{array}$ & $\begin{array}{c}19,0 \times 13,7 x \\
1,0 \mathrm{~cm}\end{array}$ & $\begin{array}{c}21,0 \times 14,5 \times \\
2 \mathrm{~cm}\end{array}$ & $\begin{array}{c}22,5 \times 15,7 x \\
0,9 \mathrm{~cm}\end{array}$ & $\begin{array}{c}20,5 \times 13,9 x \\
0,7 \mathrm{~cm}\end{array}$ \\
\hline $\mathbf{N}^{\circ}$ de páginas & 44 & 102 & 154 & 218 & 96 & 128 \\
\hline $\mathbf{N}^{\circ}$ de palavras & 812 & 15.240 & 19.219 & 18.682 & 18.326 & 30.760 \\
\hline $\begin{array}{c}\text { Média de } \\
\text { palavras por } \\
\text { página }\end{array}$ & 18 & 149 & 125 & 86 & 191 & 240 \\
\hline $\begin{array}{l}\mathbf{N}^{\circ} \text { caracteres } \\
\text { sem espaço }\end{array}$ & 4.147 & 73.533 & 92.397 & 92.559 & 88.288 & 151.328 \\
\hline $\begin{array}{l}\mathbf{N}^{\circ} \text { caracteres } \\
\text { com espaço }\end{array}$ & 4.834 & 88.142 & 110.726 & 109.694 & 105.904 & 181.769 \\
\hline $\mathbf{N}^{\circ}$ de imagens & 25 & 17 & 110 & 320 & 44 & 18 \\
\hline $\begin{array}{l}\% \text { de imagens } \\
\text { por página }\end{array}$ & $57 \%$ & $17 \%$ & $71 \%$ & $147 \%$ & $46 \%$ & $14 \%$ \\
\hline
\end{tabular}

Fonte: elaborado pelo autor.

O uso de mais de uma cor no miolo do livro é predominante no corpus analisado. Dos seis livros investigados, apenas Diário de um banana e O rapto do garoto de ouro têm o miolo em preto e branco (P\&B). As cores parecem exercer um papel importante na atratividade dos livros infantojuvenis. Embora Diário de um banana seja $P \& B$, é razoável supor que a quantidade de imagens, bem acima da média de outros livros, acaba sobrepujando a falta de cores do miolo.

O papel usado no miolo dos livros infantojuvenis apresenta, geralmente, uma gramatura maior do que a da maioria dos livros para o público adulto. Isso torna os livros mais resistentes ao manuseio e evita que as imagens e as ilustrações 
de uma página apareçam no verso de outra, algo comum em livros impressos em papéis de baixa gramatura.

A gramatura do papel tem forte interferência na espessura do livro, aumentando a sua lombada e tornando-o mais, digamos, robusto. Uma gramatura de $90 \mathrm{~g} / \mathrm{m}^{2}$, ou acima disso, deixa o livro, como produto, mais atraente. Especialmente no caso dos livros infantojuvenis, muitas vezes dados às crianças e aos pré-adolescentes como presente por amigos e parentes, ser considerado um "bom presente" diz respeito não só ao texto, mas também à materialidade, à aparência física do livro.

Ainda sobre o tipo de papel dos livros infantojuvenis, os amarelados, como o polén bold, parecem predominar nos livros com miolo P\&B, como em Crônicas 1 , pois são papéis que tornam a leitura mais confortável.

No entanto, no caso dos livros com ilustrações coloridas, em que a fidelidade em relação às cores originais é desejável e o uso de papéis amarelados poderia interferir no resultado da impressão, nota-se a predominância de papéis brancos, como os que foram utilizados em Diário de Pilar na Grécia (couché matte), Malala, a menina que queria ir para a escola (alta alvura) e Amoras (alta alvura).

O formato brochura predomina em relação ao capa dura. Talvez isso se deva não exatamente à preferência do leitor, mas principalmente ao custo e, consequentemente, ao preço. Do ponto de vista estético, a capa dura, por um lado, torna o livro mais "nobre" e, portanto, um objeto ou presente mais "valorizado", além de proteger e prolongar a vida útil do livro. Por outro lado, pode dificultar o manuseio, especialmente por "mãos pequenas" de crianças e pré-adolescentes.

A ausência de "orelhas" é outro ponto curioso dos livros analisados. Aparentemente não há motivos para não as ter, pois elas protegem as capas e servem de abrigo a sinopses, biografias de autores, entre outros paratextos que costumam frequentá-las. Entretanto, com exceção de Diário de um banana, que por ser de capa dura, não comportaria orelhas, apenas 0 rapto do garoto de ouro as tem. 
É possível que tal ausência se dê exclusivamente pela simplificação do processo editorial e pelo barateamento do livro, especialmente para aqueles que se destinam aos programas governamentais e não podem ultrapassar o orçamento por exemplar estabelecido nos editais. A ausência das orelhas permite que esses livros sejam impressos em larga escala, em impressoras rotativas e sem a necessidade de dobras e cortes adicionais, como quando se tem orelhas.

Quanto ao tamanho, os livros infantojuvenis adotam formatos menores. No corpus analisado, a única exceção é o título Amoras, que usa um formato de 20,6 cm de altura por 20,6 cm de largura e privilegia imagens, cores e texturas, atingindo crianças de uma faixa etária menor, para a qual tipicamente os livros são impressos em grandes formatos.

No que se refere à quantidade de páginas, a maioria dos livros infantojuvenis tem cerca de 100 , e o número de palavras fica entre 15.000 e 20.000. Destoam desses números os livros: Amoras, com apenas 44 páginas e 812 palavras, e, no extremo oposto, O rapto do garoto de ouro, ultrapassando a marca de 30.000 palavras.

Um indicador que chamou bastante a atenção no caso de Diário de um banana, que poderia ser aqui batizado de "densidade textual", é a quantidade de palavras por página ( $p / p)$ Nesse livro, ela é de $86 p / p$ - valor bem abaixo das 240 $\mathrm{p} / \mathrm{p}$ de 0 rapto do garoto de ouro e até mesmo das $124 \mathrm{p} / \mathrm{p}$ do ricamente ilustrado Diário de Pilar na Grécia. Esse indicador ajuda a elucidar a suspeita de que existe uma certa satisfação do leitor infantojuvenil na conclusão de um número maior de páginas, ou seja, ser capaz de ler muitas páginas seria algo que funcionaria como uma espécie de gatilho motivacional para esses leitores; algo que os deixa orgulhos perante pais, familiares e colegas, uma espécie de "conquista".

A baixa quantidade de palavras por página de Diário de um banana, que é resultado de uma combinação entre uma diagramação com espaços generosos, uma fonte de tamanho avantajado e muitas imagens, enseja a suspeita de que 
concluir um livro de 218 páginas, em pouco tempo (porque na verdade a quantidade de palavras é de 18.326), tem impacto positivo no engajamento dos meninos entre 8 e 12 anos na leitura.

Outro indicador apurado nesta pesquisa que parece ter forte poder de atração sobre os leitores é o percentual de imagens por página. Diário de um banana apresenta uma taxa de 147\% de imagens por página, ou seja, mais de uma ilustração, em média, por página. Algumas delas chegam a ter três imagens. Essas imagens ilustram o que está escrito textualmente, mas às vezes suprimem o texto, passando a sê-lo, seja pela própria evidência da ilustração, seja pela presença dos diálogos nos balões. Não há uma única forma. Esse livro é uma espécie de texto "multigênero", se assim fosse possível denominá-lo, pois em determinados momentos se comporta como um romance, em outros como uma HQ ou simplesmente uma tirinha. Essa "mistura" de gêneros editoriais parece quebrar o ritmo do livro, permitindo que o leitor salte partes sem comprometer o entendimento e, finalmente, mantenha-se engajado na leitura sem abandonar o livro.

\subsection{Outros aspectos}

Além dos aspectos já mencionados, verificou-se a presença de outros elementos que, potencialmente, possam ter atraído compradores e leitores e, dessa forma, contribuído para que os livros do corpus tenham se tornado best-sellers.

Dos seis títulos analisados, quatro pertencem a coleções. A coleção Diário de um banana apresenta quinze títulos da série e mais quatro livros especiais. Diário de Pilar também é uma série, com sete livros e um caderno. A coleção Para gostar de ler, da qual o livro Crônicas 1 faz parte, tem 47 volumes e reúne crônicas e textos de autores renomados. O rapto do garoto de ouro também integra uma coleção, a Vaga-Lume, com 105 títulos já publicados entre 1973 e 2020 e mais 25 títulos da coleção Vaga-Lume Júnior. A questão das coleções parece contribuir não só para a 
manutenção dos leitores até o final da leitura, mas para despertar neles o anseio pelo título seguinte à medida em que vão lendo e gostando de cada livro.

Do corpus, os títulos Amoras e Malala: a menina que queria ir para a escola não são parte de coleções. No entanto, ambos denotam outra tendência forte no segmento infantojuvenil, a de abordar temas sociais relevantes. Em Amoras, o autor, o conhecido rapper Emicida, trata da temática racial, abordando com extrema delicadeza e ternura a valorização da cor e da cultura negras. No livro sobre Malala, a temática é a misoginia e a luta das "mulheres" paquistanesas (Malala tinha 15 anos quando foi alvejada com um tiro no rosto) pelo direito à educação, num país dominado pelo regime Talibã.

De todos os livros analisados, os da coleção Diário de Pilar demonstram uma característica única entre os demais: a didática. A série procura intercalar as aventuras da protagonista com uma espécie de "giro" pela região visitada, seja a Grécia - como no título analisado neste artigo -, seja a Amazônia. Existe uma preocupação explícita em introduzir elementos culturais, localidades e outros aspectos da região em que a aventura transcorre, numa espécie de romance didático-histórico-geográfico. Esse tipo de livro denuncia a intenção de alguns editores de incluir essas obras nos programas de aquisição de livros para alunos e bibliotecas públicas; uma estratégia para, inclusive, torná-los best-sellers, pois quando se trata desse tipo de compra, os volumes de exemplares adquiridos costumam ultrapassar a casa dos milhões de unidades.

Por último, o preço de capa desses livros - preço de tabela definido pela editora -, na versão impressa, situa-se entre $R \$ 29,90$ e $R \$ 49,90$, o que revela um patamar mediano em termos de precificação de livros no Brasil. Todos eles, com exceção do livro Crônicas 1, apresentam também a versão e-book, na faixa de $\mathrm{R} \$ 20,00$. Nenhum dos títulos traz versão audiobook, pelo menos até 4 dezembro de 2020, quando este artigo foi finalizado. 


\section{CONCLUSÕES E CAMINHOS}

Retoma-se aqui a questão inicial e o propósito deste artigo, que é identificar as potenciais causas do desinteresse pela leitura dos meninos em relação às meninas, na faixa etária entre 8 e 12 anos, e ao mesmo tempo investigar e levantar quais elementos concernentes ao livro poderiam colaborar para evitar tal desinteresse e, até mesmo, incentivar os meninos a ingressar na leitura e fazer dela um hábito por toda a vida. Foram mapeados alguns caminhos, mesmo que ainda prematuros e passíveis de aprofundamento, para o desenvolvimento de novos títulos, traduzidos ou inéditos, capazes de atrair e engajar esses jovens leitores, quais sejam:

- Meninos se interessam menos pela leitura e/ou leem menos do que as meninas por várias questões, entre as quais: desenvolvimento posterior da linguagem em relação às meninas; maior interesse por outras atividades fora do horário da escola e que, portanto, concorrem com a leitura, como jogos eletrônicos; desinteresse pelos títulos tipicamente oferecidos e/ou exigidos pela escola ou professor (em geral do sexo feminino).

- Meninos preferem títulos com a presença de humor e aventura, de mais fácil compreensão e narrativa não linear, em que partes possam ser lidas sem perder o sentido, mesmo que algumas delas sejam "saltadas".

- Meninos preferem livros recheados de ilustrações, com menos palavras por página, letras grandes, espaços generosos entrelinhas e nas margens.

- Meninos têm muita satisfação em ler muitas páginas por vez e em concluir a leitura completa do livro. Essa velocidade afeta diretamente a motivação e o engajamento na leitura, como uma espécie de performance.

- Meninos (e meninas também) se sentem muito atraídos pelas capas dos livros, o que é fundamental para que tomem a iniciativa ou sejam receptivos à leitura. 
Esses "caminhos", levantados a partir da bibliografia consultada e do exame minucioso das obras do corpus, constituem "pistas" para autores, editoras, editores e publishers no sentido de desenvolver projetos editoriais capazes de contribuir para reverter ou, no mínimo, mitigar a falta de interesse dos meninos e a distância deles em relação às meninas no que se refere à leitura.

\section{REFERÊNCIAS}

ANDRADE, Carlos Drummond de; et al. Crônicas 1. 28. ed. São Paulo: Ática, 2000.

BRASIL. Lei no 8.069 de 13 de julho de 1990. Estatuto da Criança e do Adolescente. Diário Oficial da União. Brasília, 16 jul. 1990. Disponível em:

http://www.planalto.gov.br/ccivil 03/leis/18069.htm. Acesso em: 4 dez. 2020.

BRASIL. Ministério da Educação. Resolução nº 2, de 9 de outubro de 2018. Define Diretrizes Operacionais complementares para a matrícula inicial de crianças na Educação Infantil e no Ensino Fundamental, respectivamente, aos 4 (quatro) e aos 6 (seis) anos de idade. Diário Oficial da União. Brasília, 10 out. 2018. Disponível em: http://portal. mec.gov.br/index.php?option=com docman\&view=download\&alias=118441 -pceb007-19\&category slug=julho-2019-pdf\&ltemid=30192.

CARRANCA, Adriana. Malala, a menina que queria ir para a escola. 1. ed. São Paulo: Companhia das Letrinhas, 2015.

EMICIDA. Amoras. 1. ed. [s.l.]: Companhia das Letrinhas, 2018.

INSTITUTO PRÓ-LIVRO. Retratos da leitura no Brasil. São Paulo: Instituto Pró-Livro, 2020.

KINNEY, Jeff. Diário de um banana 1. 31. ed. Cotia: VR Editora, 2008.

LOVELESS, Tom. How well are american students learning? With sections on the gender gap in reading, effects of the common core, and student engagement. The 2015 Brown Center Report on American Education, v. 3, n. 4., 2015.

MARINAK, Barbara; GAMBRELL, Linda. Reading motivation: exploring the elementary gender gap. Literacy research and instruction, v. 49, p. 129-141, 11 mar. 2010. Disponível em: https://doi.org/10.1080/19388070902803795. Acesso em: 4 dez. 2020.

PINHEIRO, Marta Passos. A construção da infância e da adolescência: formação e aprisionamento da literatura infantil e juvenil. In V SEMINÁRIO DE LITERATURA INFANTIL 
E JUVENIL, 5, 2012, Florianópolis, SC. Anais eletrônicos...Florianópolis, 2012. Disponível em: http://alb.org.br/arquivo-

morto/edicoes anteriores/anais15/Sem09/martapassos.htm. Acesso em: 4 dez. 2020.

PINHEIRO, Marta Passos.; TOLENTINO, Jessica Andrade. Literatura infantil e juvenil: campo, materialidade e produção. 1. ed. Belo Horizonte: Moinhos, 2019.

REY, Marcos. $O$ rapto do garoto de ouro. 12. ed. [s.I.]: Global Editora, 2005.

SCHOLASTIC. Kids \& Family Reading Report Home. Disponível em:

https://www.scholastic.com/readingreport/home.html. Acesso em: 4 dez. 2020.

SILVA, Flávia Lins e; PENNA, Joana. Diário de Pilar na Grécia. 2. ed. [s.I.]: Pequena Zahar, 2010.

TYRE, Peg. The trouble with boys: a surprising report card on our sons, their problems at school, and what parents and educators must do. Illustrated ed. New York: Harmony, 2009.

WIMPY KID. Behind the Scenes with Jeff Kinney. YouTube, 6 nov. 2014. Disponível em: https://www.youtube.com/watch?v=dS4sInQMeio. Acesso em: 4 dez. 2020.

\section{Marcelo Amaral de Moraes}

Mestre em Administração, editor, publisher e revisor técnico marcelo@gruporota.com.br 